\title{
Association of Hospital Admission Service Structure With Early Transfer to Critical Care, Hospital Readmission, and Length of Stay
}

\author{
G. Randy Smith Jr., MD, MS, SFHM ${ }^{1 \star}$, Madeleine Ma, MS², Luke O. Hansen, MD, MHS, FHM¹, Nick Christensen, BS ${ }^{1}$, \\ Kevin J. O'Leary, MD, MS, SFHM'
}

${ }^{1}$ Division of Hospital Medicine, Feinberg School of Medicine, Northwestern University, Chicago, Illinois; ${ }^{2}$ Biostatistics Collaboration Center, Feinberg School of Medicine, Northwestern University, Chicago, Illinois.

BACKGROUND: Hospital medical groups use various staffing models that may systematically affect care continuity during the admission process.

OBJECTIVE: To compare the effect of 2 hospitalist admission service models ("general" and "admitter-rounder") on patient disposition and length of stay.

DESIGN: Retrospective observational cohort study with difference-in-difference analysis.

SETTING: Large tertiary academic medical center in the United States.

PARTICIPANTS: Patients $(n=19,270)$ admitted from the emergency department to hospital medicine and medicine teaching services from July 2010 to June 2013.

INTERVENTIONS: Admissions to hospital medicine staffed by 2 different service models, compared to teaching service admissions.

MEASUREMENTS: Incidence of transfer to critical care within the first 24 hours of hospitalization, hospital and emergency department length of stay, and hospital readmission rates $\leq 30$ days postdischarge.
RESULTS: The change of hospitalist services to an admitter-rounder model was associated with no significant change in transfer to critical care or hospital length of stay compared to the teaching service (difference-in-difference $P=0.32$ and $P=0.87$, respectively). The admitter-rounder model was associated with decreased readmissions compared to the teaching service on difference-in-difference analysis (odds ratio difference: $-0.21, P=0.01$ ). Adoption of the hospitalist admitter-rounder model was associated with an increased emergency department length of stay compared to the teaching service (difference of +0.49 hours, $P<0.001$ ).

CONCLUSIONS: Rates of transfer to intensive care and overall hospital length of stay between the hospitalist admission models did not differ significantly. The hospitalist admitter-rounder admission service structure was associated with extended emergency department length of stay and a decrease in readmissions. Journal of Hospital Medicine 2016;11:669-674. (C) 2016 Society of Hospital Medicine
Hospital admission represents a time period during which patients are at risk for poor clinical outcomes. Although some risk is directly generated by illness pathophysiology, some additive risk is generated by the emergency department (ED)-inpatient service handover inherent in the admission process. ${ }^{1}$ Increased risk of suboptimal outcomes can result from ED overcrowding, which has been associated with increased mortality, difficulty in patient disposition, and delays in provision of care. ${ }^{2}$ Inpatient bed occupancy, as well as availability and organization of accepting inpatient service healthcare staff, can affect ED overcrowding as well. ${ }^{3,4}$

\footnotetext{
${ }^{\star}$ Address for correspondence and reprint requests: G. Randy Smith Jr., MD, Division of Hospital Medicine, Feinberg School of Medicine, Northwestern University, 211 East Ontario Street, Suite 7-713, Chicago, IL 60611; Telephone: 312-926-5893; Fax: 312-926-4588; E-mail: gsmith2@ nm.org

Additional Supporting Information may be found in the online version of this article.

Received: January 8, 2016; Revised: March 2, 2016; Accepted: March 17,2016

2016 Society of Hospital Medicine DOI 10.1002/jhm.2592

Published online in Wiley Online Library (Wileyonlinelibrary.com).
}

The overwhelming majority of hospitalist groups accept a significant portion of their admissions via the ED. ${ }^{5}$ Hospitalist services must balance their daily group workload between ongoing care and discharge of inpatients and the activity of admitting new patients to their service. Two major models of admission processing exist for hospitalist groups to accomplish these competing tasks. One model, called the "general model," employs the use of individual hospitalists to simultaneously perform admission activity as well as ongoing ward-based care for inpatients during their workday. In the general model, a hospitalist who admits patients on their first hospital day will generally continue to see them on their second hospital day. The other model, called the "admitter-rounder model," divides the hospitalist daily group workflow between hospitalists who are assigned to perform only admission activity ("admitters"), and hospitalists who are assigned to perform only ongoing care for patients who are already admitted ("rounders"). In the admitter-rounder model, the admitter on a patient's first hospital day will generally not serve as the patient's rounder on subsequent hospital days.

Limited evidence exists to guide hospitalist groups on which model their service design should adopt. 
Conflicting evidence exists as to whether the fragmentation of care generated by an admitter-rounder admission model is beneficial or harmful. ${ }^{6-9}$ Increased availability of attending inpatient physicians during the ED-inpatient admission process has been associated with improved hospital mortality and decreased readmissions in hospital settings outside the United States, where attending availability may otherwise be limited. ${ }^{10-12}$ Separation of admission and rounding activity within a hospitalist workforce may allow each group of hospitalists to provide more timely and effective care related to their respective tasks. Our division implemented a change from a general model to an admitter-rounder model of care on January 2, 2012. We hypothesized that changing from a general admission model to an admitter-rounder model of care would be associated with a decreased rate of transfer to the intensive care unit (ICU) $\leq 24$ hours after floor arrival and shortened ED length of stay (LOS), due to improved availability of hospitalists during the admission process. Due to the introduction of discontinuity, we hypothesized that adoption of the admitterrounder model would be associated with a prolongation of hospital LOS and no overall effect on $\leq 30$ day postdischarge readmission rate. We sought to examine the relationship between our division's service design change and our hypothesized variables of interest.

\section{METHODS}

\section{Setting and Study Design}

We retrospectively evaluated electronic medical records of patients admitted between July 1, 2010 and June 30, 2013 from the ED to medical floor beds at Northwestern Memorial Hospital, an academic tertiary care teaching hospital located in Chicago, Illinois, under care of either a hospital medicine independent service or a medical teaching service. Admissions for care in observation units, service intake via interhospital or intrahospital transfers of care, or direct admissions from outpatient clinics that bypassed the ED were excluded, as was any patient with incomplete data, leaving 19,270 hospitalizations available for analysis. Each hospital medicine service was comprised of a single hospitalist with only clinical care responsibilities for the workday and no ICU or outpatient clinic responsibilities, with routine handover of the service to a hospitalist colleague every 7 days. Each medical teaching service was comprised of a supervising attending (often a hospitalist), a resident, 1 to 2 interns, and 1 to 3 medical students; the residents and interns maintained outpatient clinic responsibilities of 1 to 2 half days per service week. Inpatients on all teams were localized to hospital beds assigned to their care team. Regardless of hospitalist service design, 3 or more hospitalists were available each day to perform daytime admissions. Throughout the study period, both the hospital medicine and medicine teaching services utilized a group of physicians separate from the day teams to perform admissions and cross-coverage at night, and the teaching services maintained a generalist model of daytime admission practice. All teams accepted new admissions every day. All ED admissions involved a phone-based signout of transfer of care to the person admitting for the accepting ward team, followed by transfer of the patient to the floor, independent of whether the accepting team met the patient in the ED prior to transfer. None of the accepting inpatient services in the study had a formal right to refuse acceptance of patients referred for admission by the ED. The time period evaluated was constrained to avoid the effect of other service changes that took place before or after the study period. The Northwestern University Institutional Review Board approved the study (STU00087387).

\section{Data Acquisition and Measures}

Data were obtained from the Northwestern Memorial Hospital Enterprise Data Warehouse, an integrated repository of all clinical and research data for patients receiving care in the system. For analysis, the patients were separated into 4 groups: a prechange general admission hospitalist group (group 1), a postchange admitter-rounder hospitalist group (group 2), and 2 teaching service control groups separated according to the prechange or postchange time period (groups 3 and 4 , respectively). The primary outcome variable for the study was transfer of the patient to the ICU within 24 hours of inpatient floor arrival, which has been previously reported as an adverse outcome related to the admission process due to its association with increased inpatient mortality. ${ }^{13}$ Secondary outcome variables included ED LOS, total hospital LOS, and readmission to Northwestern Memorial Hospital within 30 days of hospital discharge. Data on unexpected transfer to the operating room, discharge against medical advice (all within 24 hours of arrival to the ward), as well as mortality during the hospital stay were collected but not further analyzed due to the extremely low incidence of each. Covariables measured included each admitted patient's age, sex, race, Elixhauser composite score (a patient comorbidity score associated with inpatient mortality, described by van Walraven et al. $^{14}$ ), case mix, insurance payer status, patient census on the accepting service for day 2 of the admitted patient's hospitalization, and hospital occupancy on the day of admission. ${ }^{7,14-16}$ Hospital occupancy was calculated as the sum of the number of beds occupied at midnight plus the number of patients discharged during the previous 24 hours, divided by the number of hospital beds, as defined by Forster et al. ${ }^{16}$

\section{Statistical Analysis}

Prestudy sample size calculation using an $\alpha$ value of 0.05 and $\beta$ value of 0.2 to detect a $1.5 \%$ absolute 
TABLE 1. Study Group Covariate Characteristics

\begin{tabular}{|c|c|c|c|c|c|c|c|c|}
\hline & $\begin{array}{c}\text { Group } 1 \\
\text { Hospitalist } \\
\text { General, } \\
\mathrm{N}=8,465\end{array}$ & $\begin{array}{c}\text { Group } 2 \\
\text { Hospitalist } \\
\text { Admitter-Rounder, } \\
\mathrm{N}=6,291\end{array}$ & $\begin{array}{c}\text { Group } 3 \\
\text { Teaching } \\
\text { Prechange, } \\
\mathrm{N}=2,636\end{array}$ & $\begin{array}{c}\text { Group } 4 \\
\text { Teaching } \\
\text { Postchange, } \\
N=1,878\end{array}$ & $\begin{array}{l}\text { Group } 2 \text { vs } \\
\text { Group 1, } \\
\text { P Value }\end{array}$ & $\begin{array}{l}\text { Group } 4 \text { vs } \\
\text { Group } 3, \\
\text { P Value }\end{array}$ & $\begin{array}{l}\text { Group } 1 \text { vs } \\
\text { Group 3, } \\
\text { PValue }\end{array}$ & $\begin{array}{c}\text { Group } 2 \text { vs } \\
\text { Group 4, } \\
\text { PValue }\end{array}$ \\
\hline Age, y, mean (SD) & $61.2(18.4)$ & $61.9(19.0)$ & $60.1(19.1)$ & $60.0(18.6)$ & 0.03 & 0.88 & 0.009 & $<0.001$ \\
\hline Female sex, $n(\%)$ & $4,423(52.3)$ & $3,298(52.4)$ & $1,440(54.6)$ & $1,031(54.9)$ & 0.83 & 0.86 & 0.03 & 0.06 \\
\hline White race, $n(\%)$ & $4,096(48.4)$ & $2,927(46.5)$ & $1,261(47.8)$ & $880(46.9)$ & 0.03 & 0.52 & 0.62 & 0.80 \\
\hline Payer status & & & & & $<0.001$ & 0.001 & 0.07 & $<0.001$ \\
\hline Medicaid, $n(\%)$ & $1,121(13.2)$ & $811(12.9)$ & $393(14.9)$ & $222(11.8)$ & & & & \\
\hline Medicare, $n(\%)$ & $4,475(52.9)$ & $3,521(56.0)$ & $1,394(52.9)$ & $961(51.2)$ & & & & \\
\hline Private, $n(\%)$ & $2,218(26.2)$ & $1,442(22.9)$ & $674(25.6)$ & $525(28.0)$ & & & & \\
\hline Self-pay, $n(\%)$ & $299(3.5)$ & $273(4.3)$ & $72(2.7)$ & $88(4.7)$ & & & & \\
\hline Other, $n(\%)$ & $352(4.2)$ & $244(3.9)$ & $103(3.9)$ & $82(4.4)$ & & & & \\
\hline Elixhauser composite score, mean (SD) & $5.3(6.7)$ & $6.6(7.3)$ & $5.6(7.0)$ & $6.4(7.3)$ & $<0.001$ & 0.007 & 0.05 & 0.30 \\
\hline Inpatient mortality, $n(\%)$ & $74(0.9)$ & $70(1.1)$ & $31(1.2)$ & $18(1.0)$ & 0.14 & 0.51 & 0.15 & 0.62 \\
\hline No. of patients seen by accepting service, mean (SD) & $10.2(3.8)$ & $12.0(3.1)$ & $6.3(3.2)$ & $7.0(3.3)$ & $<0.001$ & $<0.001$ & $<0.001$ & $<0.001$ \\
\hline Hospital \% occupancy at admission, mean (SD) & $1.23(0.18)$ & $1.20(0.17)$ & $1.23(0.18)$ & $1.20(0.17)$ & $<0.001$ & $<0.001$ & 0.61 & 0.43 \\
\hline Case mix, $n(\%)$ & & & & & $<0.001$ & $<0.001$ & $<0.001$ & $<0.001$ \\
\hline Diseases of the circulatory system & $2,695(31.8)$ & $1,173(18.9)$ & $396(15.0)$ & $292(15.6)$ & & & & \\
\hline Other & $1,139(13.5)$ & $1,151(18.3)$ & $423(16.1)$ & $292(15.6)$ & & & & \\
\hline Diseases of the respiratory system & $883(10.4)$ & $612(9.7)$ & $314(11.9)$ & $541(28.9)$ & & & & \\
\hline Diseases of the digestive system & $923(10.9)$ & $889(14.1)$ & $420(15.9)$ & $196(10.4)$ & & & & \\
\hline Diseases of the genitourinary system & $492(5.8)$ & $525(8.4)$ & $230(8.7)$ & $122(6.5)$ & & & & \\
\hline Injury and poisoning & $517(6.1)$ & $451(7.2)$ & $182(6.9)$ & $80(4.3)$ & & & & \\
\hline $\begin{array}{l}\text { Endocrine, nutritional, and metabolic } \\
\text { diseases and immunity disorders }\end{array}$ & $473(5.6)$ & $357(5.7)$ & $194(7.4)$ & $76(4.1)$ & & & & \\
\hline $\begin{array}{l}\text { Symptoms, signs, and ill-defined conditions } \\
\text { and factors influencing health status }\end{array}$ & $470(5.6)$ & $267(4.2)$ & $141(5.4)$ & $63(3.4)$ & & & & \\
\hline $\begin{array}{l}\text { Diseases of the musculoskeletal system } \\
\text { and connective tissue }\end{array}$ & $371(4.4)$ & $281(4.5)$ & $136(5.1)$ & $58(3.1)$ & & & & \\
\hline Infectious and parasitic diseases & $234(2.8)$ & $288(4.6)$ & $108(4.1)$ & $98(5.2)$ & & & & \\
\hline Diseases of the blood and blood-forming organs & $268(3.2)$ & $297(4.7)$ & $92(3.5)$ & $60(3.2)$ & & & & \\
\hline
\end{tabular}

NOTE: Abbreviations: SD, standard deviation.

difference in ICU transfer rate between postchange study groups, with a patient distribution ratio of $3.3: 1$ or higher between the admitter-rounder and teaching postchange groups, and an assumed higher transfer rate in the teaching postchange group, revealed a requirement of at least 1068 hospitalizations in the teaching postchange group for our evaluation. Descriptive statistics were calculated for each patient group. Firth's logistic regressions were used to model the odds of patient being transfer to ICU within 24 hours after arrival and the odds of hospital readmission within 30 days after discharge, adjusting for confounders. ${ }^{17}$ Quantile regressions were used to model the change in the median of ED LOS and the median of hospital LOS due to the rightskewed distributions of LOS. Based on the clinical relevance to the outcomes, models were adjusted for patients' measured covariates. All covariates that were significant at $\alpha=0.05$ level were considered significant. All statistical analyses were performed in SAS version 9.4 (SAS Institute Inc., Cary, NC).

\section{RESULTS}

\section{Patient Characteristics}

The characteristics of the 4 patient populations are listed in Table 1. Compared to the general admission hospitalist group, the admitter-rounder hospitalist group was more likely to be older (admitter-rounder $61.9 \pm 19.0$ vs $61.2 \pm 18.4, P=0.03)$, a Medicare beneficiary $(56.0 \%$ vs $52.9 \%, P<0.001)$, have a higher Elixhauser composite score $(6.6 \pm 7.3$ vs 5.3 $\pm 6.7, P<0.001)$, and less likely to be white $(46.5 \%$ vs $48.4 \%, P=0.03)$. The teaching service patient characteristics changed over time only with regard to Elixhauser composite score (teaching postchange 6.4 \pm 7.3 vs $5.6 \pm 7.0, P<0.001)$; except for case mix, all other covariates did not change significantly between prechange and postchange teaching services. There was no significant difference in Elixhauser composite score between hospitalist and teaching services during the study period. Hospitalist groups were more likely than teaching service groups to have older patients, both before (hospitalist $61.2 \pm 18.4$ vs teaching $60.1 \pm 19.1, P=0.009$ ) and after (hospitalist $61.9 \pm 18.0$ vs teaching $60.0 \pm 18.6, P<0.001$ ) the hospitalist admission system change. Compared to teaching groups, hospitalist groups were less likely to have female patients before the system change (hospitalist $52.3 \%$ vs $54.6 \%, P=0.03$ ), and more likely to have Medicare beneficiaries after the system change (hospitalist $56.0 \%$ vs $51.1 \%, P<0.001$ ). Significant differences in case mix existed in all comparisons among all 4 study groups. 
TABLE 2. Study Group Results

\begin{tabular}{|c|c|c|c|c|}
\hline & $\begin{array}{l}\text { Group 1, Hospitalist } \\
\text { General, N = 8,465 }\end{array}$ & $\begin{array}{c}\text { Group 2, } \\
\text { Hospitalist } \\
\text { Admitter-Rounder, } \\
\mathrm{N}=6,291\end{array}$ & $\begin{array}{c}\text { Group } 3, \\
\text { Teaching Prechange, } \\
N=2,636\end{array}$ & $\begin{array}{c}\text { Group } 4 . \\
\text { Teaching Postchange, } \\
N=1,878\end{array}$ \\
\hline Transfer to ICU $\leq 24$ hours after ward arrival, $n(\%)$ & $235(2.8)$ & $139(2.2)$ & $75(2.9)$ & $59(3.1)$ \\
\hline Hospital readmission $\leq 30$ days after discharge, $n(\%)$ & $1,924(22.7)$ & $1,546(24.6)$ & $608(23.1)$ & $504(26.8)$ \\
\hline \multicolumn{5}{|l|}{ Emergency department length of stay, $h$} \\
\hline Mean (SD) & $6.9(3.36)$ & $7.39(3.9)$ & $7.05(2.98)$ & $6.89(3.03)$ \\
\hline Median [range] & $6.22[0.22-62.47]$ & $6.68[0.62-149.52]$ & $6.53[1.98-33.63]$ & $6.3[2.02-24.17]$ \\
\hline \multicolumn{5}{|l|}{ Hospital length of stay, h } \\
\hline Mean (SD) & $102.46(120.14)$ & $125.94(153.41)$ & $114.07(165.62)$ & $122.89(125.55)$ \\
\hline Median [range] & $67.37[0.52-1,964.07]$ & $88.18[0.28-5,801.28]$ & $71.5[4.57-5,131.37]$ & $88.08[4.73-1,262.58]$ \\
\hline
\end{tabular}

NOTE: Abbreviations: SD, standard deviation.

\begin{tabular}{|c|c|c|c|}
\hline & $\begin{array}{c}\text { Hospitalist } \\
\text { Admitter-Rounder vs } \\
\text { Hospitalist General }\end{array}$ & $\begin{array}{c}\text { Teaching } \\
\text { Postchange vs } \\
\text { Teaching Prechange }\end{array}$ & $\begin{array}{l}\text { Difference-in-Difference } \\
\text { Value Parameter Estimate } \\
\text { [Standard Error], } P \text { Value }\end{array}$ \\
\hline $\begin{array}{l}\text { Transfer to ICU } \leq 24 \text { hours after floor arrival, OR } \\
(95 \% \text { confidence interval) }\end{array}$ & $1.292(1.026-1.629)$ & $1.029(0.721-1.468)$ & $\mathrm{OR}:+0.22[ \pm \quad 0.22], 0.32$ \\
\hline $\begin{array}{l}\text { Hospital readmission } \leq 30 \text { days after discharge, OR } \\
99 \% \text { confidence interval) }\end{array}$ & $1.048(0.966-1.136)$ & $1.298(1.127-1.495)$ & OR: $-0.21[ \pm 0.08], 0.01$ \\
\hline $\begin{array}{l}\text { Emergency department length of stay, median hours } \\
\text { Hospital length of stay, median hours }\end{array}$ & $\begin{array}{l}+0.40 \\
+12.96\end{array}$ & $\begin{array}{r}-0.09 \\
+13.36\end{array}$ & $\begin{array}{l}+0.49[ \pm 0.09],<0.001 \\
-0.39[ \pm 2.44], 0.87\end{array}$ \\
\hline
\end{tabular}

NOTE: All results adjusted for all measured covariates. Abbreviations: ICU, intensive care unit; $\mathrm{OR}$, odds ratio.

\section{Impact of the Admission System on Outcomes}

Measured unadjusted primary and secondary outcomes for the 4 study groups, as well as inpatient mortality, are listed in Table 2. Comparative odds ratios (ORs) for the outcomes of transfer to ICU $\leq 24$ hours of floor arrival and readmission to hospital $\leq 30$ days after discharge, median (50\% quantile) regression results for the outcomes of ED and hospital LOS, each adjusted by all study covariates, as well as associated difference-in-difference parameter estimates with associated standard error (SE) ranges and $P$ values, are listed in Table 3. Difference-in-difference analysis of outcomes associated with adoption of the hospitalist admitter-rounder system compared to the time-matched teaching service revealed no statistically significant difference in associated ICU transfer outcome between hospitalist or teaching services (admitter-rounder OR difference of +0.22 , SE $\pm 0.22, P=$ 0.32 ). A significant decrease in associated odds for hospital readmission $\leq 30$ days postdischarge was noted when adoption of the hospitalist admitterrounder system was compared to the time-matched teaching service (admitter-rounder OR difference of -0.21 , SE $\pm 0.08, P=0.01$ ). Adoption of the hospitalist admitter-rounder system, compared to the timematched teaching service, was associated with a significant increase in ED LOS (admitter-rounder difference of +0.49 hours, SE $\pm 0.09, P<0.001)$. Difference-indifference analysis revealed no significant difference in associated hospital LOS between the hospitalist and time-matched teaching services over the study period (admitter-rounder difference of -0.39 hours, SE $\pm 2.44, P=0.87)$.

\section{DISCUSSION}

Our observations were revealing for a statistically nonsignificant trend toward increased ICU transfers $\leq 24$ hours after floor arrival after adoption of the admitter-rounder model by the hospital medicine service. Despite prior publication of early transfer to the ICU being associated with adverse outcomes, including increased inpatient mortality, we observed no difference in mortality in our study groups. ${ }^{13}$ We suspect that earlier transfer to the ICU in our study cohort may instead represent a protective action taken more frequently by admitting hospitalists in the admitterrounder model in response to provider discontinuity risks embedded in the admission process. Requests for transfer to the ICU at our institution require approval by the ICU team, and requests from attending hospitalists may be responded to differently from requests enacted by teaching team members, which as a factor also may account for some of the adjusted differences in transfer incidence. Taken together, increased availability 
of hospitalists during the admission process may result in earlier implementation of an overall lower threshold for implementation of ICU transfer. Our conclusion is limited by our study cohort's overall inpatient mortality rate, which is sufficiently low to preclude further assessment of the relationship of adverse outcomes with ICU transfer rate in our study groups. Therefore, clinical significance of our primary outcome findings, as well as the workload factors that impact ICU transfers initiated by hospitalist and teaching services, require further examination.

Despite a hypothesized increase in hospital LOS caused by additional discontinuity of hospitalist care in the admitter-rounder model, adoption of the admitterrounder model was not associated with an increased hospital LOS. We suspect this finding may represent the presence of action(s) proximal to the admission process, on the part of either admission and/or "rounding" hospitalists, which decrease hospital LOS to a degree offsetting the expected LOS increase generated by provider discontinuity. Examples of such actions include more efficient testing or consultation, or improved detection of diagnostic errors.

Adoption of the admitter-rounder model by the hospital medicine service was also associated with decreased hospital readmission rates compared to the timematched teaching service. We suspect that assignment of daily discharge and admission service activity to separate hospitalists in the admitter-rounder model may allow more opportunity for "rounder" hospitalists to engage in activity protective against readmissions, such as greater direct engagement with postdischarge resources, or improved hospitalist availability for multidisciplinary inpatient efforts focused on discharge planning.

Adoption of the admitter-rounder model was found to be associated with a median 29-minute increase in ED LOS compared to the time-matched teaching service. As a floor team member's physical presence in the ED was not required for ED-floor transfer during the study period, increased physical availability of admitting hospitalists in the admitter-rounder model may allow for increased opportunity for a hospitalist to disrupt ED-specific workflows related to patient transfer (eg, disruption of transportation service activity by an earlier bedside visit from the admitting hospitalist). Hospitalists in the general model were allowed to leave after performing their daily duties, whereas admitting hospitalists in the admitter-rounder model were assigned to stay for a timed shift, regardless of the completion of admissions; the difference in duty assignment may be associated with different hospitalist behaviors during the admission process. Improved ease for ED staff to contact hospitalist staff in the admitter-rounder model may have led ED staff to prioritize other tasks more demanding of their continuous engagement at the expense of initiating admissions, thereby paradoxically delaying admissions to hospital medicine.
Other studies exist that attempt to describe changes in admission service structure, particularly with regard to housestaff admission activity in relation to changes in resident work hours. Many of these studies vary with regard to implementation of separate physician teams for day and night coverage, or are focused on a specific medical condition, thereby limiting their applicability to a hospital medicine service free of work-hour restrictions and engaged in care of a wide variety of medical conditions. ${ }^{18-20}$ In contrast, our study is an attempt to examine, in isolation, outcomes associated with adoption of an admitter-rounder model of care as a specific discontinuity risk during the admission process, within the context of a stable system of night coverage in place for all medical teams engaged in admission activity of undifferentiated medical patients.

Limitations of our study include the inability to ascertain causality of observed outcomes, due to our observational study design. Our study was of a single hospital, which may limit applicability of our results to other hospital environments. However, the admission models examined in our study are common among hospital medicine groups. Clinically relevant outcome metrics, such as mortality and unexpected transfer to the operating room, were measured but of too low incidence to allow for further meaningful analysis. The clinical consequences and workflow practices that correlate with our study's findings likely require case review and time-motion analyses, respectively, to further delineate the relevance of our findings; these analyses were outside of the scope of our study, and further investigation is required. In summary, our observations suggest that adoption by hospitalist services of an admitter-rounder model of care for admissions is associated with a decreased rate of hospital readmission $\leq 30$ days after discharge, with no effect on median hospital LOS, a statistically nonsignificant trend toward more ICU transfers in the first 24 hours of a patient's hospital stay, and a slight increase in median ED LOS.

\section{Acknowledgements}

This study was conducted with logistical support, software, and computer hardware provided by the Division of Hospital Medicine, Department of Medicine, Northwestern University Feinberg School of Medicine, and by the Biostatistics Collaboration Center, Northwestern University Feinberg School of Medicine.

Disclosure: Nothing to report.

\section{References}

1. Reisenberg LA, Leitzsch J, Massucci JL, et al. Residents' and attending physicians' handoffs: a systematic review of the literature. Acad Med. 2009;84(12):1775-1787.

2. Bernstein SL, Aronsky D, Duseja R, et al. The effect of emergency department crowding on clinically oriented outcomes. Acad Emerg Med. 2009;16:1-10.

3. Rathlew NK, Chessare J, Olshaker J, et al. Time series analysis of variables associated with daily mean emergency department length of stay. Ann Emerg Med. 2007;49:265-271.

4. Howell E, Bessman E, Kravet S, et al. Active bed management by hospitalists and emergency department throughput. Ann Intern Med. 2008; 149:804-810.

5. Society of Hospital Medicine. 2014 state of hospital medicine report. 2014:22. 
6. Epstein K, Juarez E, Epstein A, Loya K, Singer A. The impact of fragmentation of hospitalist care on length of stay. J Hosp Med. 2010;5: $335-338$.

7. O'Leary KJ, Turner J, Christensen N, et al. The effect of hospitalist discontinuity on adverse events. J Hosp Med. 2015;10:147-151.

8. Schaffer AC, Puopolo AL, Raman S, Kachalia A. Liability impact of the hospitalist model of care. J Hosp Med. 2014;9:750-755.

9. Wachter RM. Does continuity of care matter? No: discontinuity can improve patient care. West J Med. 2001;175(1):5.

10. Bell D, Lambourne A, Percival F, Laverty AA, Ward DK. Consultant input in acute medical admissions and patient outcomes in hospitals in England: a multivariate analysis. PLoS One. 2013;8(4): e61476.

11. Scott I, Vaughan L, Bell D. Effectiveness of acute medical units in hospitals: a systematic review. Int J Qual Health Care. 2009;21(6):397-407.

12. Smith GR Jr, Stein J, Jones M. Acute medicine in the United Kingdom: first-hand perspectives on a parallel evolution of inpatient medical care. J Hosp Med. 2012:7(3);254-257.

13. Liu V, Kipnis P, Rizk NW, et al. Adverse outcomes associated with delayed intensive care unit transfers in an integrated healthcare system. J Hosp Med. 2012;7(3):224-230.
14. Van Walraven C, Austin PC, Jennings A, Quan H, Forster AJ. A modification of the Elixhauser comorbidity measures into a point system for hospital death using administrative data. Med Care. 2009;47(6):626-633.

15. Elliott DJ, Young RS, Brice J, Agular R, Kolm P. Effect of hospitalist workload on the quality and efficiency of care. JAMA Intern Med. 2014;174(5): 786-793.

16. Forster AJ, Stiell I, Wells G, Lee AJ, van Walraven C. The effect of hospital occupancy on emergency department length of stay and patient disposition. Acad Emerg Med. 2003;10(2):127-133.

17. Firth D. Bias reduction of maximum likelihood estimates. Biometrika. 1993;80(1):27-38.

18. Desai S, Feldman L, Brown L, et al. Effect of the 2011 vs 2003 duty hour regulation-compliant models on sleep duration, trainee education, and continuity of patient care among internal medicine house staff. JAMA Intern Med. 2013;173(8):649-655.

19. Lofgren RP, Gottlieb D, Williams RA, Rich EC. Post-call transfer of resident responsibility: Its effect on patient care. J Gen Intern Med. 1990;5:501-505.

20. Schuberth JL, Elasy TA, Butler J, et al. Effect of short call admission on length of stay and quality of care for acute decompensated heart failure. Circulation. 2008;117:2637-2644. 